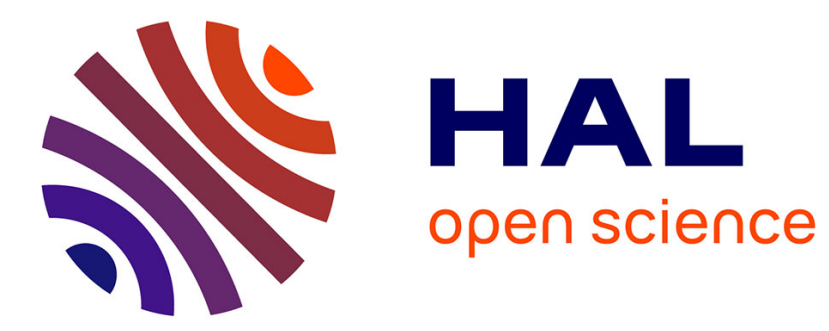

\title{
Disappointed in You, Angry about Your Offer: Distinct Negative Emotions Induce Concessions via Different Mechanisms
}

Gert-Jan Lelieveld, Eric van Dijk, Ilja van Beest, Wolfgang Steinel, Gerben A. van Kleef

\section{To cite this version:}

Gert-Jan Lelieveld, Eric van Dijk, Ilja van Beest, Wolfgang Steinel, Gerben A. van Kleef. Disappointed in You, Angry about Your Offer: Distinct Negative Emotions Induce Concessions via Different Mechanisms. Journal of Experimental Social Psychology, 2011, 10.1016/j.jesp.2010.12.015 . hal-00962266

\section{HAL Id: hal-00962266 https://hal.science/hal-00962266}

Submitted on 21 Mar 2014

HAL is a multi-disciplinary open access archive for the deposit and dissemination of scientific research documents, whether they are published or not. The documents may come from teaching and research institutions in France or abroad, or from public or private research centers.
L'archive ouverte pluridisciplinaire HAL, est destinée au dépôt et à la diffusion de documents scientifiques de niveau recherche, publiés ou non, émanant des établissements d'enseignement et de recherche français ou étrangers, des laboratoires publics ou privés. 


\section{Accepted Manuscript}

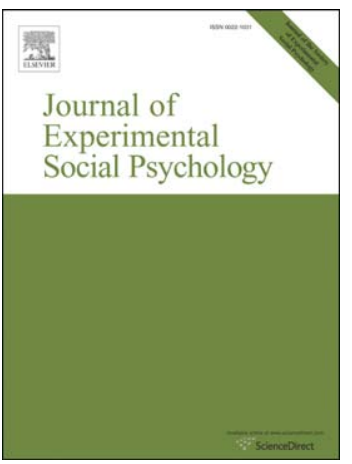

Disappointed in You, Angry about Your Offer: Distinct Negative Emotions Induce Concessions via Different Mechanisms

Gert-Jan Lelieveld, Eric Van Dijk, Ilja Van Beest, Wolfgang Steinel, Gerben A. Van Kleef

PII:

S0022-1031(10)00283-0

DOI:

doi: 10.1016/j.jesp.2010.12.015

Reference:

YJESP 2592

To appear in: Journal of Experimental Social Psychology

Received date: $\quad 3$ July 2010

Please cite this article as: Lelieveld, G.-J., Van Dijk, E., Van Beest, I., Steinel, W. \& Van Kleef, G.A., Disappointed in You, Angry about Your Offer: Distinct Negative Emotions Induce Concessions via Different Mechanisms, Journal of Experimental Social Psychology (2010), doi: $10.1016 / j . j e s p .2010 .12 .015$

This is a PDF file of an unedited manuscript that has been accepted for publication. As a service to our customers we are providing this early version of the manuscript. The manuscript will undergo copyediting, typesetting, and review of the resulting proof before it is published in its final form. Please note that during the production process errors may be discovered which could affect the content, and all legal disclaimers that apply to the journal pertain. 
Disappointed in You, Angry about Your Offer:

Distinct Negative Emotions Induce Concessions via Different Mechanisms

\author{
Gert-Jan Lelieveld and Eric Van Dijk \\ Leiden University \\ Ilja Van Beest \\ Tilburg University \\ Wolfgang Steinel \\ Leiden University \\ Gerben A. Van Kleef \\ University of Amsterdam
}

Word count: 4990

Author Note

Correspondence concerning this article should be addressed to Gert-Jan Lelieveld,

Department of Social and Organizational Psychology, Leiden University, P.O. Box 9555, 2300 RB Leiden, The Netherlands. Phone: +31(0) 71 - 5276615. E-mail: lelieveldgj@fsw.leidenuniv.nl 


\begin{abstract}
Does it help or hurt to communicate negative emotions in bargaining? In this article, we propose that behavioral effects are dependent on the type of negative emotion that is communicated and whether such emotions are directed at the offer or the person. We show that the two negative emotions anger and disappointment have opposing effects in negotiations: anger pays when it is directed at the offer, but disappointment pays when it is directed at the person. Offer-directed anger elicits higher offers than person-directed anger, because people infer higher limits from opponents who communicate offer-directed anger. Person-directed disappointment elicits higher offers in others than offer-directed disappointment, because it evokes higher feelings of guilt. Our findings thus show that the interpersonal effects of anger and disappointment in negotiation depend critically on the target of the emotion, and that their effects can be explained by different processes.
\end{abstract}

Keywords: Negotiations; Interpersonal effects of emotions; Social influence; Anger; Disappointment. 
Disappointed in You, Angry about Your Offer:

Distinct Negative Emotions Induce Concessions via Different Mechanisms

Negotiation is often a heated and highly emotional process. Research suggests that anger and disappointment are two of the most often expressed negative emotions in bargaining (Van Dijk \& Zeelenberg, 2002). According to social-functional analyses of emotions (e.g., Keltner \& Haidt, 1999; Parkinson, 1996; Van Kleef, 2009), such emotional expressions convey crucial information about the feelings and intentions of the sender, and this in turn has behavioral consequences for receivers. In negotiations, communicated emotions may therefore affect opponents' behavior. We argue that while anger and disappointment are both negative emotions, they may have markedly different effects on opponents in negotiations.

Although anger and disappointment may both be reactions to undesirable outcomes, research has shown that these emotions have very different appraisal patterns (e.g., Frijda, Kuipers, \& Ter Schure, 1989). Anger arises when a person's goals are frustrated and s/he blames someone else for it. It is associated with a tendency to aggress against the person (or object) seen as responsible for the goal blockage (Averill, 1982; Fischer \& Roseman, 2007; Van Kleef, De Dreu, \& Manstead, 2010). Disappointment, on the other hand, arises when progress towards a goal is below expectations (Carver \& Scheier, 1990; Van Kleef \& Van Lange, 2008) and/or when a desired outcome is not achieved (Bell, 1985; Frijda, 1986; Van Dijk \& Van Der Pligt, 1997). Also, Van Dijk and Zeelenberg (2002) found that the experience of disappointment is associated with feelings of weakness (i.e., disappointed individuals feel like they have little control over the event), more so than the experience of anger (see also Frijda et al., 1989). 
Based on these insights, one might expect that in bargaining, anger and disappointment influence opponents via different processes. With respect to the communication of anger, previous research has shown clear effects on bargaining behavior. In particular, anger has been shown to communicate toughness and high limits (Clark, Pataki, \& Carver, 1996; Karasawa, 2001; Sinaceur, \& Tiedens, 2006; Van Kleef, De Dreu, \& Manstead, 2004a, b). People with high limits have high demands and are not expected to give in. Anger therefore alerts opponents to possible negative consequences (e.g., conflict escalation), which leads them to concede to avoid costly impasse. But does communicating anger always elicit concessions? In the present paper, we argue that the effects of anger depend on the target of the emotion, that is, whether it is directed at the bargainer's offers or at the bargainer as a person. When anger is directed at the offer, participants use the opponent's emotion to assess his or her limits, and concede more. When anger is person-directed and thus not directly connected to the offer, it is less informative about one's limits. As a result, person-directed anger is less seen as being an indication of high limits (Van Kleef, 2009). Accordingly, Steinel, Van Kleef, and Harinck (2008) found that offer-directed anger induced concessions, but person-directed anger did not. People may thus obtain higher outcomes when they communicate offer-directed than person-directed anger.

As noted above, disappointment is, relative to anger, more associated with feelings of weakness. Disappointed bargainers may thus not be seen as bargainers with high limits and high demands. Based on this, one might be tempted not to communicate disappointment. In the current paper, however, we argue that it can be an effective bargaining strategy, but primarily when it is person-directed. More specifically, we argue that concessions are most likely to emerge in the case of person-directed disappointment instead of when it is offer-directed, because this type 
of disappointment is more likely to evoke guilt in others, and thus make them more willing to give in.

It has been demonstrated that disappointment may evoke guilt. Ferguson, Olthof, and Stegge (1997) presented participants with guilt-eliciting scenario's and showed that the victim's anticipated disappointment was highly (positively) correlated with the participant's feelings of guilt. Importantly, however, disappointment may not always evoke guilt. We argue that especially person-directed disappointment is likely to evoke guilt in others.

Our proposition that person-directed disappointment is more likely to evoke guilt (and thus to yield positive effects) connects to previous research by Van Dijk and Zeelenberg (2002), who distinguished between two types of disappointment: outcome-related disappointment and person-related disappointment. The authors found that outcome-related disappointment involves feelings and intentions which are more self-focused (outcomes are lower than expected), whereas feelings and intentions involved with person-related disappointment are more other- and relationship focused (the undesirable situation is attributed to another person). In contrast to offer-directed disappointment, person-directed disappointment thus indicates a transgression that threatens the social relationship and makes people feel socially responsible. These are key antecedents of the experience of guilt. That is, people have been shown to feel guiltier when they have a concern for the other and feel socially responsible (Baumeister, Stillwell, \& Heatherton, 1994; Branscombe, Doosje, \& McGarty, 2002; Mallet \& Swim, 2007). The communication of persondirected disappointment therefore may evoke more guilt in opponents than offerdirected disappointment. Moreover, since guilt motivates people to make amends (Baumeister et al., 1994) and concessions (Ketelaar \& Au, 2003), we propose that 
person-directed disappointment evokes larger concessions than offer-directed disappointment.

In sum, we argue that the interpersonal effects of negative emotions in negotiations depend critically on how they are communicated. Communicated anger elicits higher offers when it is offer-directed, because it affects the participant's appraisals of the opponent's limits. Conversely, communicated disappointment elicits higher offers when it is person-directed, because this triggers more guilt than when it is offer-directed. We conducted two experiments to investigate these propositions.

\section{Experiment 1}

As a first test of our ideas, we presented participants a brief negotiation scenario where they were asked how they would perceive an opponent who communicated anger or disappointment directed at the offer or at the person. We expected (1) offer-directed anger to elicit more concessions than person-directed anger, mediated by the appraisal of the opponent's limits, and (2) person-directed disappointment to elicit more concessions than offer-directed disappointment, mediated by guilt.

\subsection{Method}

1.1.1. Design and participants. Eighty students from Leiden University (49 females, 31 males, $M_{\text {age }}=21.55, S D=2.83$ ) were randomly assigned to a 2 (opponent's emotion: anger vs. disappointment) $\times 2$ (target: offer-directed vs. persondirected) between-participants design.

1.1.2. Procedure. Depending on condition, participants read a scenario where they negotiated with someone who communicated anger or disappointment, directed at the offer or the person. The scenario read as follows (translated from Dutch): 
You are negotiating with another person. During the negotiation this person claims to be [angry at/disappointed in] [your offer/you as a person]. Even though you have little information of this person, we want to ask you some questions about this person and how this person comes across.

1.1.3. Measures. Participants indicated their agreement with a number of statements on 10-point Likert-type scales $(1=$ very unlikely, $10=$ very likely $)$. We assessed participant's guilt by asking how guilty they would feel, and the appraisal of the opponent's limits by asking how much they thought the opponent would give in during the negotiation. Finally, we asked participants to what extent they would make high demands during the negotiation.

\subsection{Results}

1.2.1. Appraisal of the opponent's limits. We submitted participants' appraisals of the opponent's limits to a 2 (opponent's emotion) $\times 2$ (target) Analysis of Variance (ANOVA), which revealed main effects of emotion, $F(1,76)=18.50, p<$ $.001, \eta^{2}=.20$, and target, $F(1,76)=10.07, p<.005, \eta^{2}=.12$. These main effects were qualified by an interaction, $F(1,76)=10.98, p<.005, \eta^{2}=.13$ (see Table 1$)$. Simpleeffect analyses revealed that there was no effect of target on the perceived limits ratings in the disappointment conditions $(p=.92)$. In the anger conditions there was an effect of target, $F(1,76)=21.04, p<.001, \eta^{2}=.22$, such that participants in the offer-directed anger condition judged the limits of opponents to be higher than participants in the person-directed condition. Simple-effect analyses showed that participants in the offer-directed anger condition also perceived their opponent's limits to be higher than participants in the offer- and person-directed disappointment conditions $(p s<.001)$. 
1.2.2. Participant's guilt. A $2 \times 2$ ANOVA showed a main effect of target, $F(1,76)=9.89, p<.005, \eta^{2}=.12$, which was qualified by a significant interaction effect, $F(1,76)=5.50, p<.05, \eta^{2}=.07$ (see Table 1$)$. Simple-effect analyses revealed that there was no effect of target in the anger conditions $(p=.57)$. In the disappointment conditions, however, there was a significant effect of target, $F(1,76)$ $=15.07, p<.001, \eta^{2}=.17$. Participants in the person-directed disappointment condition indicated they would feel guiltier than participants in the offer-directed disappointment condition. Simple-effect analyses revealed that participants in the person-directed disappointment condition also felt guiltier than participants in both anger conditions $(p s<.005)$.

1.2.3. Demands. Finally, a $2 \times 2$ ANOVA on demands yielded the predicted interaction effect, $F(1,76)=49.74, p<.001, \eta^{2}=.40$ (see Table 1$)$. Simple-effects analyses revealed that a) offer-directed anger elicited larger concessions (lower demands) than person-directed anger, $F(1,76)=40.06, p<.001, \eta^{2}=.35$, and $b$ ) offer-directed disappointment elicited smaller concessions (higher demands) than person-directed disappointment, $F(1,76)=13.28, p<.001, \eta^{2}=.15$.

1.2.4. Mediation analyses. We anticipated the effect of target of the emotion on demands in the anger condition to be mediated by participants' appraisals of their opponent's limits, and the effect in the disappointment condition to be mediated by guilt. To test these predictions, we conducted two sets of mediated regression analyses using the procedure described by Baron and Kenny (1986).

In the anger conditions we found a significant effect of target of the emotion on demands, $\beta=-.68, p<.001$, and a significant effect of target on the appraisals of the opponent's limits, $\beta=-.67, p<.001$. Adding appraisals of the other's limits to the equation produced a significant effect of appraisals, $\beta=.76, p<.001$, and reduced the 
formerly significant effect of target on demands to non-significance, $\beta=-.17, p=.11$.

A Sobel test revealed that the reduction was significant, $Z=-4.40, p<.001$.

In the disappointment conditions we found a significant effect of target on demands, $\beta=.56, p<.001$, and a significant effect of target on guilt, $\beta=.66, p<$ .001 . Adding guilt produced a significant effect of guilt, $\beta=.83, p<.001$, and reduced the formerly significant effect of target on demands to non-significance, $\beta=$ $.02, p=.89$. A Sobel test revealed that the reduction was significant, $Z=4.30, p<$ .001 .

\subsection{Discussion}

In line with our reasoning, participants indicated they would offer more to opponents who communicated offer-directed anger and person-directed disappointment, than to opponents who communicated person-directed anger and offer-directed disappointment. Anger pays more when it is offer-directed, because then it is more informative about one's limits. Disappointment, on the other hand, pays more when it is person-directed, because then it evokes more guilt.

Study 1 provided first evidence that the two negative emotions anger and disappointment can have opposing effects in bargaining. Although the findings support our reasoning, it should be noted that we used a scenario setting in which participants had to imagine a negotiation and report on their behavioral intentions. To extend our findings, we conducted a second experiment in which participants engaged in a more involving negotiation task. This task enabled us to study actual behavior, and to assess additional measures that could further substantiate our claims.

\section{Experiment 2}

In Experiment 2 participants performed a commonly used task to study negotiation behavior (e.g., Pietroni, Van Kleef, De Dreu, \& Pagliaro, 2008; Steinel et 
al., 2008; Van Kleef et al., 2004a, b). In this task participants negotiated as a seller with a potential buyer for six rounds. During the negotiation they received emotional reactions from their opponent. This task allowed us to study actual behavior in an involving negotiation setting and to investigate whether the effects and underlying processes uncovered in Experiment 1 can be replicated with a behavioral measure.

In addition to measuring negotiation behavior and the mediating constructs of guilt and inferred limits, we also collected measures to see whether the communication of anger and disappointment differs in other respects as well. In particular, one might wonder whether disappointment may be a less intense form of anger and that that could drive our effects. Also, one might wonder whether both emotions differ in terms of appropriateness (e.g., whether people maybe feel it is less appropriate to communicate anger than disappointment). We therefore assessed the perceived intensity and appropriateness of the emotional reactions.

\subsection{Method}

2.1.1. Design and participants. Ninety-seven students from Leiden University ( 75 females, 22 males, $M_{\text {age }}=20.75, S D=1.90$ ) who participated in a laboratory study for monetary compensation were randomly assigned to the conditions of a 2 (opponent's emotion: anger vs. disappointment) $\times 2$ (target: offerdirected vs. person-directed) between-participants factorial design.

2.1.2. Procedure. Participants were seated in cubicles equipped with a computer that was connected through a network. They learned that they would negotiate via the computer with another participant. The negotiation task was an adapted version of the one used by Van Kleef et al. (2004a, b), which captures the main characteristics of real-life negotiation - that is, multiple issues differing in utility to the negotiator, information about one's own payoffs only, and the typical offer- 
counteroffer sequence. Participants learned that they were assigned the role of seller of a consignment of mobile phones and that their objective was to negotiate with the buyer about the price, the warranty period, and the duration of the service contract. They were then presented with a payoff chart (see Table 2) that showed which outcomes were most favorable to them, and they learned that their objective was to earn as many points as possible. To give an example, Level 3 on price, Level 4 on warranty and Level 5 on service, yielded a total of 495 points $(300+75+120)$. The corresponding payoff table of the other party was not displayed, and participants were told only that it differed from their own.

To enhance involvement, we informed participants that points would be converted to lottery tickets at the end of the experiment and that the more points earned, the more lottery tickets one would obtain and the greater would be one's chance of winning a 30 Euro prize. To emphasize the mixed-motive nature of the negotiation, we told participants that only those who reached agreement would participate in the lottery. There were thus incentives to earn as many points as possible, but at the same time to reach an agreement.

Subsequently, the negotiation started, and the buyer (i.e., the computer) made a first offer. Over the negotiation rounds the buyer proposed the following levels of agreement (for price-warranty-service): 8-7-8 (round 1), 8-7-7 (round 2), 8-6-7 (round 3), 7-6-7 (round 4), 7-6-6 (round 5), and 6-6-6 (round 6). Past research has shown that this preprogrammed strategy has face validity and is seen as intermediate in cooperativeness and competitiveness (De Dreu \& Van Lange, 1995). A demand by the participant was accepted if it equaled or exceeded the offer the computer was about to make in the next round. If no agreement was reached by the sixth round, the negotiation was interrupted (see De Dreu \& Van Lange, 1995). Following Tripp and 
Sondak (1992) and Van Kleef et al. (2004a, b), participants who reached agreement before round $6(N=17)$ were excluded from the analyses. This allowed us to track participants' behavior across the entire negotiation and to compare participants with a similar history. (Retaining these participants yielded a similar pattern of results.)

2.1.3. Emotion manipulation. After the first, third, and fifth negotiation rounds, participants received information about the buyer's intentions. We stressed that the buyer did not know that his/her intentions were revealed to the participant (as in Van Kleef et al., 2004a). The intentions contained the manipulation of the opponent's emotion (anger vs. disappointment) and the emotion's target (offerdirected vs. person-directed). That is, after round one the buyer wrote "I think I will offer 8-7-7", which would indeed be his/her offer. This intention information also contained an emotional statement which constituted the emotion manipulation. Half of the participants read an emotional reaction that was offer-directed and the other half read one directed at the person (see Table 3). These and similar statements have been successfully used in previous research (e.g., Steinel et al., 2008; Van Kleef, De Dreu, \& Manstead, 2006; Van Kleef \& Van Lange, 2008).

2.1.4. Dependent measures. We transformed the participants' offers on the three issues into an index revealing the negotiator's total level of demand in each round (i.e., the sum of the number of points asked for each issue; see Table 2), and also averaged the demand levels in the six rounds into an index of the negotiator's average demands (see e.g. De Dreu, Carnevale, Emans, \& Van De Vliert, 1994).

We asked participants to indicate on a 9-point scale how guilty they felt during the negotiation $(1=$ not guilty at all, $9=$ very guilty $)$. Participants' estimates of the opponent's limits were measured with six items, two for each issue (“e.g., What do you think was the buyer's lowest acceptable level of agreement on 
[price/warranty/service]?”, see also Steinel et al., 2008), and were averaged into a single index $(\alpha=.89)$. In addition, to assess the intensity of the emotion and appropriateness of the emotional reaction, we asked participants on a 9-point scale (1 $=$ not at all, $9=$ very much so) how negative they thought the opponent's reaction was, and to what extent they thought the emotional reaction was appropriate in the current situation.

To check the emotion manipulation, we asked participants to what extent they thought their opponent was angry and to what extend he or she was disappointed during the negotiation. To check the manipulation of the target of the emotion, we asked participants to indicate how much they agreed with two statements, namely "The emotions of the buyer were directed at me personally" and "The emotions of the buyer were directed at the offer." We recoded the latter and averaged both ratings into a single index $(\alpha=.80)$.

\subsection{Results}

2.2.1. Manipulation checks. We submitted the participants' ratings of their opponent's anger and disappointment to a $2 \times 2$ ANOVA. Results on the anger ratings only yielded a main effect of emotion, $F(1,76)=58.38, p<.001, \eta^{2}=.43$, indicating that participants in the anger condition rated their opponent as angrier $(M=7.82, S D$ $=1.72)$ than participants in the disappointment condition $(M=4.35, S D=2.26)$. Results on the disappointment ratings also only yielded a main effect of opponent's emotion, $F(1,76)=14.84, p<.001, \eta^{2}=.16$. Participants in the disappointment condition judged the opponents as more disappointed $(M=7.35, S D=1.75)$ than participants in the anger condition $(M=5.52, S D=2.39)$.

A $2 \times 2$ ANOVA on the index of person-directedness of the opponent's emotion revealed only a significant main effect of target, $F(1,76)=23.98, p<.001$, 
$\eta^{2}=.24$, indicating that participants in the offer-directed condition reported less person-directedness $(M=2.99, S D=1.65)$ than did participants in the person-directed emotion condition $(M=5.31, S D=2.47)$.

2.2.2. Demands. Demands in rounds $1-6$ were submitted to a $2 \times 2$ mixedmodel ANOVA, with emotion and target as between-participants variables and demands in rounds 1-6 as a repeated-measures variable. First of all, the analysis yielded a main effect of round, $F(5,380)=215.15, p<.001, \eta^{2}=.74$, indicating that participants' demands declined over time (the average demands in round 1 and 6 were 667.00 and 434.50 , respectively).

Secondly, and most important, we obtained a significant three-way interaction between emotion, target and round, $F(5,380)=3.14, p<.01, \eta^{2}=.04$, indicating that the interactive effect of emotion and round on participant's demands was moderated by the target of the emotion. This three-way interaction is displayed in Figure 1.

To facilitate mediation analysis (see below) we also analyzed the demand level data by calculating the mean demands over the six rounds, as we explained in the method section (see dependent measures). A $2 \times 2$ ANOVA on demands yielded the predicted interaction between emotion and target, $F(1,76)=12.33, p<.001, \eta^{2}=.14$. Means and standard deviations are shown in Table 4. Simple-effects analyses revealed that a) offer-directed anger elicited larger concessions (lower demands) than persondirected anger, $F(1,76)=5.62, p<.05, \eta^{2}=.07$, and $\mathrm{b}$ ) offer-directed disappointment elicited smaller concessions (higher demands) than person-directed disappointment, $F(1,76)=6.74, p<.05, \eta^{2}=.08$.

2.2.3. Appraisal of the opponent's limits. A $2 \times 2$ ANOVA revealed main effects of emotion, $F(1,76)=5.19, p<.05, \eta^{2}=.06$, and target, $F(1,76)=14.11, p<$ $.001, \eta^{2}=.16$. More important for our reasoning, these main effects were qualified by 
an interaction, $F(1,76)=11.08, p<.005, \eta^{2}=.13$ (see Table 4). Simple-effect analyses revealed that there was no effect of target of the perceived limits ratings in the disappointment conditions $(p=.76)$. However, as predicted, there was an effect of target in the anger conditions, $F(1,76)=25.07, p<.001, \eta^{2}=.25$. Participants in the offer-directed anger condition judged the limits of opponents to be higher than did participants in the person-directed condition. Simple-effect analyses showed that participants in the offer-directed anger condition also perceived their opponent's limits to be higher than did participants in the offer- and person-directed disappointment conditions $(p s<.001)$.

2.2.4. Participant's guilt. A $2 \times 2$ ANOVA on the guilt ratings also yielded main effects of emotion, $F(1,76)=9.11, p<.005, \eta^{2}=.11$, and target, $F(1,76)=$ 4.72, $p<.05, \eta^{2}=.06$. Again, these were qualified by an interaction, $F(1,76)=5.20$, $p<.05, \eta^{2}=.06$ (see Table 4). Simple-effect analyses revealed that there was no effect of target on the guilt ratings in the anger conditions $(p=.94)$. However, as predicted, there was an effect of target in the disappointment conditions, $F(1,76)=$ 9.92, $p<.005, \eta^{2}=.12$, such that participants felt guiltier towards opponents who were disappointed in them as a person than towards opponents who were disappointed in the offer. Simple-effect analyses revealed that participants in the person-directed disappointment condition also felt guiltier than did participants in the offer- and person-directed anger conditions $(p s<.005)$.

2.2.5. Mediation analyses. To investigate the mediating role of the appraisal of the opponent's limits in the anger conditions and guilt in the disappointment conditions, we conducted two sets of mediated regressions analyses using the procedure described by Baron and Kenny (1986). 
In the anger conditions we found a significant effect of target of the emotion on demands, $\beta=.47, p<.005$, and a significant effect of target on the appraisals of the opponent's limits, $\beta=-.53, p<.001$. Adding appraisals of the other's limits to the equation produced a significant effect of appraisal, $\beta=-.78, p<.001$, and reduced the formerly significant effect of target on demands to non-significance, $\beta=.06, p=.62$. A Sobel test revealed that the reduction was significant, $Z=3.35, p<.001$.

In the disappointment conditions we found a significant effect of target on demands, $\beta=-.33, p<.05$, and a significant effect of target on guilt, $\beta=.45, p<.005$. Adding guilt produced a significant effect of guilt, $\beta=-.41, p<.05$, and reduced the formerly significant effect of target on demands to non-significance, $\beta=-.14, p=.39$. A Sobel test revealed that the reduction was significant, $Z=-1.99, p<.05$.

\subsubsection{Additional measures.}

2.2.6.1. Emotion intensity. A $2 \times 2$ ANOVA showed no significant main effects of emotion $(p=.88)$ or target $(p=.20)$ and no interaction effect $(p=.55$; overall $M=6.45, S D=1.28$ ), indicating that the opponent's emotion was perceived as equally intense in all conditions.

\subsubsection{Appropriateness of the emotion. A $2 \times 2$ ANOVA showed no} significant main effects of emotion $(p=.68)$ or target $(p=.42)$ and no interaction effect ( $p=.73$; overall $M=6.31, S D=1.43)$, indicating that the opponent's emotion was perceived as equally appropriate in all conditions.

\section{General Discussion}

In line with a social functional analysis of emotions (e.g., Keltner \& Haidt, 1999; Van Kleef, 2009), we observe that one should be careful to generalize from one negative emotion to another. Although anger and disappointment are both negative emotions, and although the communication of both may elicit concessions, they do so 
under different circumstances and for different reasons. Anger elicits concessions when it is offer-directed and not when it is person-directed, because offer-directed anger signals high limits. In contrast, disappointment elicits concessions when it is person-directed and not when it is offer-directed because person-directed disappointment evokes guilt. Put differently, our data suggest that people give in to anger because they fear they would otherwise not reach an agreement and to disappointment because they would otherwise feel uncomfortable with themselves.

If one would assume that all negative emotions have similar effects on others, one might erroneously conclude that disappointment, like anger, communicates high limits and anger, like disappointment, evokes guilt. However, as our results show, disappointment did not communicate high limits and anger did not evoke high levels of guilt. Disappointment is associated with weakness (Frijda, Kuipers, \& Ter Schure, 1989; Van Dijk \& Zeelenberg, 2002; Van Kleef et al., 2006), and disappointed bargainers may thus not be seen as very ambitious and demanding. Instead, their limits may be judged as low, which may elicit low offers when people do not feel guilty (i.e., when it is offer-directed). Anger on the other hand is associated more with dominance (Tiedens, 2001) and previous research has shown that when people do not take their opponent's limits into account (e.g., when it is person-directed), anger is reciprocated (Van Dijk, Van Kleef, Steinel, \& Van Beest, 2008). This suggests that instead of evoking guilt, anger evokes retaliation, especially when directed at the person rather than the offer (see Steinel et al., 2008). Further research may investigate how this difference in communicated weakness between anger and disappointment influences their effect on opponent's bargaining behavior.

The fact that we observed opposing effects fits with the theoretical notion that it is essential to not only consider the valence of emotions (i.e., whether emotions are 
positive or negative). It is important to distinguish between different types of emotions, and acknowledge that specific emotions convey specific information (e.g., Lerner \& Keltner, 2000; Tiedens \& Linton, 2001; Van Kleef et al., 2006, 2010; Zeelenberg \& Pieters, 1997). One should therefore treat each emotion as a distinct predictor of behavior in negotiations. Our findings corroborate this notion, and in addition also highlight that when it comes to investigating the interpersonal effects of distinct emotions, it is important to consider the target of the emotion.

As we already noted above, anger is often reciprocated. Our results show that disappointment, on the contrary, evokes the complementary emotion guilt in others. The difference between these concepts is that emotional reciprocity refers to the process by which one individual comes to feel the emotions of another, whereas emotional complementarity occurs when one person's emotions evoke different but corresponding emotions in others (Van Kleef, Oveis, Van der Löwe, LuoKogan, Goetz, \& Keltner, 2008). In this respect, the current findings also add to the literature on emotional contagion (Hatfield et al., 1994; see also Anderson, Keltner, \& John, 2003; Hess \& Blairy, 2001; Neumann \& Strack, 2000; Wild et al., 2001), since different negative emotions emotionally affect others in a different way.

We found similar results across different types of bargaining settings (a computer-mediated bargaining setting in Experiment 2 and a scenario setting where people did not have a specific bargaining setting in mind in Experiment 1). One may, however, wonder whether similar findings would be obtained in a face-to-face negotiation. As noted before, we made an explicit decision to maintain experimental control, to permit a carefully controlled manipulation of the opponent's emotion. We have no reason to suspect that our findings are restricted to the domain of computermediated interaction. Previous research has used various settings to compare effects 
of communicated emotions. Findings obtained with computer-mediated interactions are similar to findings obtained with different paradigms, including surveys involving full-time workers (e.g., Van Kleef, De Dreu, Pietroni, \& Manstead, 2006), nonverbal manipulations of emotional expressions by means of pictures (e.g., Pietroni et al., 2008) and face-to-face negotiation (e.g., Sinaceur \& Tiedens, 2006). Future research might investigate the generalization of the interpersonal effects of the studied emotions across settings.

In our first study, the emotions may have been interpreted as an attempt to strategically influence the opponents. Although this was not possible in our second study (because participants knew that their opponents did not know that they would read their reaction), it may be interesting to find out if people strategically make use of their emotions in negotiations. One could, for instance, investigate whether people actually choose to communicate their anger at the offer and their disappointment at the person. By providing a broader and more differentiated view of how emotions can affect others, this work helps future researchers to sheds new light on the conditions under which emotions are strategically effective. 


\section{References}

Anderson, C., Keltner, D., \& John, O. P. (2003). Emotional convergence between people over time. Journal of Personality and Social Psychology, 84, 1054-1068. Averill, J. R. (1982). Anger and aggression. New York: Springer.

Baron, R. M., \& Kenny, D. A. (1986). The moderator-mediator variable distinction in social psychological research: Conceptual, strategic and statistical considerations. Journal of Personality and Social Psychology, 51, 1173-1182.

Baumeister, R. F., Stillwell, A. M., \& Heatherton, T. F. (1994). Guilt: An interpersonal approach. Psychological Bulletin, 115, 243-267.

Bell, D. E. (1985). Disappointment in decision making under uncertainty. Operations Research, 33, 1-27.

Branscombe, N. R., Doosje, B., \& McGarty, C. (2002). Antecedents and consequences of collective guilt. In D. M. Mackie \& E. R. Smith (Eds.), From prejudice to intergroup emotions: Differentiated reactions to social groups (pp. 49-66). New York: Psychology Press.

Carver, C. S., \& Scheier, M. F. (1990). Origins and functions of positive and negative affect: A control-process view. Psychological Review, 97, 19-35.

Clark, M. S., Pataki, S. P., \& Carver, V. H. (1996). Some thoughts and findings on self-presentation of emotions in relationships. In G. J. O. Fletcher \& J. Fitness (Eds.), Knowledge structures in close relationships: A social psychological approach (pp. 247-274). Mahwah, NJ: Erlbaum.

De Dreu, C. K. W., Carnevale, P. J., Emans, B. J. M., \& Van De Vliert, E. (1994). Effects of gain-loss frames in negotiation: Loss aversion, mismatching, and frame adoption. Organizational Behavior and Human Decision Processes, 60, 90-107. 
De Dreu, C. K. W., \& Van Lange, P. A. M. (1995). The impact of social value orientations on negotiator cognition and behavior. Personality and Social Psychology Bulletin, 21, 1178-1188.

Ferguson, T. J., Olthof, T., \& Stegge, H. (1997): Temporal dynamics of guilt: changes in the role of interpersonal and intrapsychic factors. European Journal of Social Psychology, 27, 659-673.

Fischer, A. H., \& Roseman, I. J. (2007). Beat them or ban them: The characteristics and social functions of anger and contempt. Journal of Personality and Social Psychology, 93, 103-115.

Frijda, N. H. (1986). The emotions. Cambridge, UK: Cambridge University Press.

Frijda, N. H., Kuipers, P., \& Ter Schure, E. (1989). Relations among emotion, appraisal, and emotional action readiness. Journal of Personality and Social Psychology, 57, 212-228.

Hatfield, E., Cacioppo, J. T., \& Rapson, R. L. (1994). Emotional contagion. New York: Cambridge University Press.

Hess, U., \& Blairy, S. (2001). Facial mimicry and emotional contagion to dynamic emotional facial expressions and their influence on decoding accuracy. International Journal of Psychophysiology, 40, 129-141.

Karasawa, K. (2001). Anger vs guilt inference of responsibility and interpersonal reactions. Psychological Reports, 89, 731-739.

Keltner, D., \& Haidt, J. (1999). Social functions of emotions at four levels of analysis. Cognition and Emotion, 13, 505-521.

Ketelaar, T., \& Au, W. T. (2003). The effects of feelings of guilt on the behaviour of uncooperative individuals in repeated social bargaining games: An affect-as- 
information interpretation of the role of emotion in social interaction. Cognition and Emotion, 17, 429-453.

Lerner, J. S., \& Keltner, D. (2000). Beyond valence: Toward a model of emotionspecific influences on judgment and choice. Cognition and Emotion, 14, 473493.

Mallett, R. K., \& Swim, J. K. (2007). The influence of inequality, responsibility and justifiability on reports of group-based guilt for ingroup privilege. Group Processes and Intergroup Relations, 10, 57-69.

Neumann, R., \& Strack, F. (2000). "Mood contagion": The automatic transfer of mood between persons. Journal of Personality and Social Psychology, 79, 211223.

Parkinson, B. (1996). Emotions are social. British Journal of Psychology, 87, 663683.

Pietroni, D., Van Kleef, G. A., De Dreu, C. K. W., \& Pagliaro, S. (2008). Emotions as strategic information: Effects of other's emotional expressions on fixed-pie perception, demands, and integrative behavior in negotiation. Journal of Experimental Social Psychology, 44, 1444-1454.

Sinaceur, M., \& Tiedens, L. (2006). Get mad and get more than even: When and why anger expression is effective in negotiations. Journal of Experimental Social Psychology, 42, 314-322.

Steinel, W., Van Kleef, G. A., \& Harinck, F. (2008): Are you talking to me? Separating the people from the problem when expressing emotions in negotiation. Journal of Experimental Social Psychology, 44, 362-369. 
Tiedens, L. Z. (2001). Anger and advancement versus sadness and subjugation: The effects of negative emotion expressions on social status conferral. Journal of Personality and Social Psychology, 80, 86-94.

Tiedens, L. Z., \& Linton, S. (2001). Judgment under emotional certainty and uncertainty: The effects of specific emotions on information processing. Journal of Personality and Social Psychology, 81, 973-988.

Tripp, T. M., \& Sondak, H. (1992). An evaluation of dependent variables in experimental negotiation studies: Impasse rates and Pareto efficiency. Organizational Behavior and Human Decision Processes, 51, 273-295.

Van Dijk, E., Van Kleef, G. A., Steinel, W., \& Van Beest, I. (2008). A social functional approach to emotions in bargaining: When communicating anger pays and when it backfires. Journal of Personality and Social Psychology, 94, $600-614$.

Van Dijk, W. W., \& Van der Pligt, J. (1997). The impact of probability and magnitude of outcome on disappointment and elation. Organizational Behavior and Human Decision Processes, 69, 277-284.

Van Dijk, W. W., \& Zeelenberg, M. (2002). What do we talk about when we talk about disappointment? Distinguishing outcome-related disappointment from person-related disappointment. Cognition and Emotion, 16, 787-807.

Van Kleef, G. A. (2009). How emotions regulate social life: The emotions as social information (EASI) model. Current Directions in Psychological Science, 18, 184-188.

Van Kleef, G. A., De Dreu, C. K. W., \& Manstead, A. S. R. (2004a). The interpersonal effects of anger and happiness in negotiations. Journal of Personality and Social Psychology, 86, 57-76. 
Van Kleef, G. A., De Dreu, C. K. W., \& Manstead, A. S. R. (2004b). The interpersonal effects of emotions in negotiations: A motivated information processing approach. Journal of Personality and Social Psychology, 87, 510528.

Van Kleef, G. A., De Dreu, C. K. W., \& Manstead, A. S. R. (2006). Supplication and appeasement in conflict and negotiation: The interpersonal effects of disappointment, worry, guilt, and regret. Journal of Personality and Social Psychology, 91, 124-142.

Van Kleef, G. A., De Dreu, C. K. W., \& Manstead, A. S. R. (2010). An interpersonal approach to emotion in social decision making: The emotions as social information model. Advances in Experimental Social Psychology, 42, 45-96.

Van Kleef, G. A., De Dreu, C. K. W., Pietroni, D., \& Manstead, A. S. R. (2006). Power and emotion in negotiation: Power moderates the interpersonal effects of anger and happiness on concession making. European Journal of Social Psychology, 36, 557-581.

Van Kleef, G. A., Oveis, C., Van der Löwe, I., LuoKogan, A., Goetz, J., \& Keltner, D. (2008). Power, distress, and compassion: Turning a blind eye to the suffering of others. Psychological Science, 19, 1315-1322.

Van Kleef, G. A., \& Van Lange, P. A. M. (2008). What other's disappointment may do to selfish people: Emotion and social value orientation in a negotiation context. Personality and Social Psychology Bulletin, 34, 1084-1095.

Wild, B., Erb, M., \& Bartels, M. (2001). Are emotions contagious? Evoked emotions while viewing emotionally expressive faces: Quality, quantity, time course, and gender differences. Psychiatry Research, 102, 109-124. 
Zeelenberg, M., \& Pieters, R. (2006). Feeling is for doing: A pragmatic approach to the study of emotions in economic behavior. In D. De Cremer, M. Zeelenberg, \& J.K. Murnighan (Eds.), Social psychology and economics (pp. 117-137).

Mahwah: Lawrence Erlbaum. 
Figure 1. Demands as a function of opponent's emotion and target of the emotion (Experiment 2).

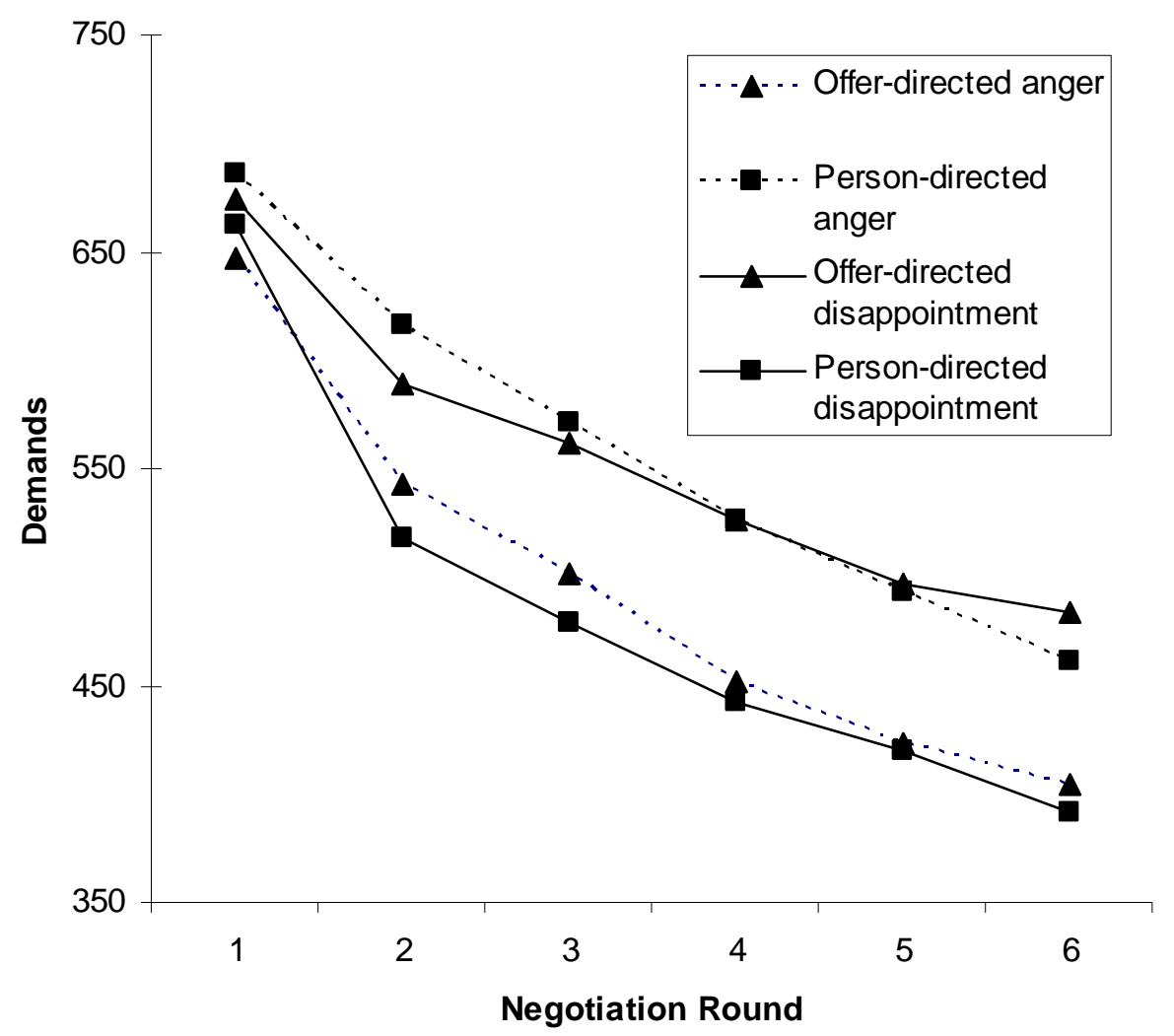


Table 1. Opponent's Guilt, Appraisal of the Opponent's Limits and Demands as a Function of Emotion and Target (Experiment 1).

Anger

\begin{tabular}{|c|c|}
\hline Offer-directed & Person-directed \\
\hline$M \quad S D$ & $S D$ \\
\hline
\end{tabular}

$\begin{array}{llllllll}7.55^{\mathrm{a}} & 1.64 & 5.25^{\mathrm{b}} & .91 & 4.85^{\mathrm{b}} & 1.42 & 4.90^{\mathrm{b}} & 2.13\end{array}$

opponent's limits

$\begin{array}{lcccccccc}\text { Guilt } & 4.85^{\mathrm{a}} & 2.28 & 5.20^{\mathrm{a}} & 2.48 & 4.60^{\mathrm{a}} & 1.14 & 7.00^{\mathrm{b}} & 1.62 \\ \text { Demands } & 6.55^{\mathrm{a}} & 1.70 & 3.25^{\mathrm{b}} & 1.97 & 4.55^{\mathrm{b}} & 1.15 & 6.45^{\mathrm{a}} & 1.67\end{array}$

Note. Participants could answer on a 10-point scale, higher scores indicate a higher

likelihood of agreement with the item. Means within rows with different superscripts differ significantly ( $p$ s $<.05$, analyzed with simple-effects analyses). 
Table 2. Participant's Payoff chart (Experiment 2).

\begin{tabular}{|c|c|c|c|c|c|c|}
\hline \multirow[b]{2}{*}{ Level } & \multicolumn{2}{|c|}{ Price of Phones } & \multicolumn{2}{|c|}{ Warranty period } & \multicolumn{2}{|c|}{ Service contract } \\
\hline & Price & Payoff & $\begin{array}{l}\text { Warranty } \\
\text { (months) }\end{array}$ & Payoff & $\begin{array}{l}\text { Service } \\
\text { (months }\end{array}$ & Payoff \\
\hline 1 & $€ 150$ & 400 & 1 & 120 & 1 & 240 \\
\hline 2 & $€ 145$ & 350 & 2 & 105 & 2 & 210 \\
\hline 3 & $€ 140$ & 300 & 3 & 90 & 3 & 180 \\
\hline 4 & $€ 135$ & 250 & 4 & 75 & 4 & 150 \\
\hline 5 & $€ 130$ & 200 & 5 & 60 & 5 & 120 \\
\hline 6 & $€ 125$ & 150 & 6 & 45 & 6 & 90 \\
\hline 7 & $€ 120$ & 100 & 7 & 30 & 7 & 60 \\
\hline 8 & $€ 115$ & 50 & 8 & 15 & 8 & 30 \\
\hline 9 & $€ 110$ & 0 & 9 & 0 & 9 & 0 \\
\hline
\end{tabular}


Table 3. Statements Used for the Manipulation of the Opponent's Emotion (Experiment 2).

Opponent's $\quad$ Reaction after round 1

Angry $\quad$ This [offer/person] makes me really angry , I think I will offer 8-7-7

Disappointed This [offer/person] really disappoints me, I think I will offer 8-7-7

Reaction after round 3

Angry This [behavior/person] is really getting on my nerves, I am going to offer 7-

Disappointed This [behavior/person] is really starting to disappoint me, I am going to offer 7-6-7

Reaction after round 5

Angry I am going to offer 6-6-6, 'cos this [negotiation/guy] pisses me off

Disappointed I am going to offer 6-6-6, 'cos this [negotiation/guy] really disappoints me

$\overline{\text { Note. Translated from Dutch. Words in brackets before the slash were used in the offer-directed }}$ emotion condition. Words in brackets after the slash were used in the person-directed emotion condition. The opponent's intended offer corresponded with the actual offer in the next round. 
Table 4. Demands, Perceived Limits and Guilt as a Function of the Opponent's Emotion and the Target of the Emotion (Experiment 2).

\section{Anger}

\begin{tabular}{llll}
\hline \multicolumn{2}{c}{ Offer-directed } & & \multicolumn{2}{c}{ Person-directed } \\
\cline { 1 - 1 } & & & \\
\hline & & $S D$
\end{tabular}

Disappointment

\begin{tabular}{llll}
\hline \multicolumn{2}{c}{ Offer-directed } & & \multicolumn{2}{c}{ Person-directed } \\
\cline { 1 - 1 } & $S D$ & & $S D$
\end{tabular}

\begin{tabular}{lcccccccc}
\hline Perceived Limits & $5.62^{\mathrm{a}}$ & 1.34 & $4.24^{\mathrm{b}}$ & .86 & $4.53^{\mathrm{b}}$ & .41 & $4.44^{\mathrm{b}}$ & .52 \\
Guilt & $4.14^{\mathrm{b}}$ & 1.46 & $4.11^{\mathrm{b}}$ & 1.63 & $4.40^{\mathrm{b}}$ & 1.14 & $5.95^{\mathrm{a}}$ & 1.91 \\
Demands & $495.23^{\mathrm{a}}$ & 72.63 & $559.39^{\mathrm{b}}$ & 47.61 & $555.54^{\mathrm{b}}$ & 114.59 & $485.38^{\mathrm{a}}$ & 91.67 \\
\hline
\end{tabular}

Note. Means within rows with different superscripts differ significantly ( $p$ s $<.05$, analyzed with simple-effects analyses). 